\title{
Hospital Pharmacy Service: thinking in the post-pandemic time
}

\author{
Serviço de Farmácia Hospitalar: pensando no período pós-pandemia
}

\begin{abstract}
Angelita Cristine MELO ${ }^{1}$ iD, Alice Ramos SILVA ${ }^{2,24}$ iD, Mario Jorge SOBREIRA-DA-SILVA ${ }^{3}$ iD, Renata Cristina NASCIMENTO4 ${ }^{(D)}$, Fernando FERNANDEZ-LLIMOS ${ }^{(1)}$, Antonio Matoso MENDES ${ }^{6}$ iD, Catarina Luz OLIVEIRA ${ }^{7}$, Cesar Augusto TEIXEIRA ${ }^{8}$ (D), Claudia Garcia OSORIO-DE-CASTRO ${ }^{9}$ D , Débora DE CARVALHO ${ }^{10}$, Eugenie Desirèe NERI ${ }^{11}$ (D) Fabio FERRACINI $^{12}$, Javier Álvarez CRIADO ${ }^{13}$ (D) , Lucila Isabel CASTRO-PASTRANA ${ }^{14} \mathbb{D}$, Luciane de Fátima CALDEIRA ${ }^{15}$ (D) Pamela BERTOLDO $^{16}$, Rodrigo ORELLANA ${ }^{17}$, Selma Rodrigues de CASTILHO ${ }^{18}$ (D) , Simone Dalla MAHMUD ${ }^{19}$, Teresa HERNÁNDEZ-GALINDO ${ }^{20}$ (D), Valéria Santos BEZERRA ${ }^{21,25}$, Valdjane SALDANHA ${ }^{22}$ (D), Vanusa Barbosa PINTO (D) ${ }^{23}$, Elisangela da Costa LIMA ${ }^{24,25}$ (iD)
\end{abstract}

\begin{abstract}
${ }^{1}$ Universidade Federal (UF) de São João Del Rei, São João Del Rei, Brasil; ${ }^{2}$ Hospital Barra D’OR; Rio de Janeiro, Brasil; ${ }^{3}$ nnstituto Nacional de Câncer, Rio de Janeiro, Brasil; ${ }^{4}$ UFOP, Ouro Preto, Brasil; ${ }^{5}$ Universidade do Porto, Porto, Portugal; ${ }^{6}$ Complexo Hospital de Clínicas da UFPR, Curitiba, Brasil; ${ }^{7}$ Hospital Vila Franca de Xira, Vila Franca de Xira e Associação Portuguesa de Farmacêuticos Hospitalares, Portugal; ${ }^{8}$ Hospital Universitário Clementino Fraga Filho, UFRJ, Rio de Janeiro, Brasil; ${ }^{9}$ Escola Nacional de Saúde Pública, Rio de Janeiro, Brasil; ${ }^{10}$ Hospital Sírio Libanês, São Paulo, Brasil; ${ }^{11}$ Complexo Hospitalar da UFC, Fortaleza, Brasil; ${ }^{12}$ Hospital Israelita Albert Einstein, São Paulo, Brasil;

${ }^{13}$ Hospital Universitario La Paz, Madrid, Espanha; ${ }^{14}$ Universidade das Américas Puebla, Puebla, México; ${ }^{15}$ Universidade Estadual do Oeste do Paraná, Cascavel, Brasil; ${ }^{16}$ Associação Argentina de Farmacêuticos Hospitalares, Argentina; ${ }^{17}$ Sociedade Chilena de Farmácia Assistencial, Chile; ${ }^{18}$ Faculdade de Farmácia, UFF, Rio de Janeiro, Brasil, ${ }^{19} \mathrm{Hospital}$ das Clinicas de Porto Alegre, Porto Alegre, Brasil; ${ }^{20}$ Universidad Nacional Autónima do México, Cidade do México, México; ${ }^{21} \mathrm{Hospital}$ da Restauração, Recife, Brasil; ${ }^{22}$ Hospital Universitário Onofre Lopes, Natal, Brasil; ${ }^{23}$ Hospital Universitário da Universidade São Paulo; São Paulo, Brasil; ${ }^{24}$ Faculdade de Farmácia, UFRJ, Rio de Janeiro, Brasil;

${ }^{25}$ Sociedade Brasileira de Farmácia Hospitalar e Serviços de Saúde, Brasil.
\end{abstract}

Corresponding Author: Lima EC: eclima.ufrj@gmail.com

Submitted: 27-11-2020 Accepted: 30-11-2020

\section{Introduction}

The COVID-19 pandemic has been requiring multiple efforts from hospital pharmacy services ${ }^{1}$. There was substantial commitment from the Pharmacy teams in the discussion and definition of strategies for the prevention and control of COVID-19, 2,3 in the management of the shortage of various supplies, ${ }^{4,5}$ and in the adaptation of the care plans to the new profile and volume of care demanded from the health services. ${ }^{6,7,8}$

During the past ten months, varied information about the pandemic was centralized and made available in webpages about the prevention, spread control, and treatment of the symptoms of the new disease in its multiple aspects. The International Pharmaceutical Federation, for example, distributed documents from the World Health Organization and from professional councils, organizations, associations and pharmacist scientific societies in more than thirty countries. ${ }^{9}$ A series of articles on the management of the services in the COVID-19 crisis was published by the Spanish Society of Hospital Pharmacy ${ }^{10}$ and the Society of Infectious Diseases Pharmacist ${ }^{11}$ and the Sociedad Chilena de Farmacia Asistencial12, made available evidenced-based reviews and newsletters, respectively., Contingency plans elaborated by the Brazilian Society of Hospital Pharmacy and Health Services (Sociedade Brasileira de Farmácia Hospitalar e Serviços de Saúde, SBRAFH $)^{13}$ and by the Ordem de Farmacêuticos de Portugal ${ }^{14}$ among others were added to these efforts.

However, in addition to the immediate actions to face the pandemic, the challenges imposed in this year 2020 brought other organizational lessons and changes that can impact on the provision of the pharmaceutical services worldwide in the short- and medium-term. This article aims at presenting the perspective of 24 specialists working in pharmaceutical research, teaching or care in six countries: Brazil, Argentina, Chile, Mexico, Spain, and Portugal.

To achieve this objective, a debate was promoted between the authors with the aid of online platforms, in the period between October $27^{\text {th }}$ and November $15^{\text {th }}$, with a proposal and reflection on the main practices and activities that suffered some influence and were modified in hospital pharmacies.

Each specialist specified the relevance of the challenges imposed on the management, logistics, distribution, and use of medications, as well as on the aspects related to human resources management during the pandemic. A Likert scale was used to classify the relevance of these aspects, with the following categories: (i) very important, (ii) important, (iii) moderately important, (iv) sometimes important, or (v) not important. ${ }^{15}$ The detailed perception of the authors was obtained from the answers recorded in an online form (Google Forms ${ }^{\circ}$ ) in three blocks of question: challenges brought by the pandemic, resulting changes for management and clinical performance, and advances and future perspectives.

\section{Main challenges}

The alerts issued by the World Health Organization about the spread of the new Coronavirus in China and in part of Europe ${ }^{16}$ seem not to have generated any immediate response from the services. Shortage of medications, sanitizing products, medical 
equipment, and other supplies were the main challenge for the management of hospital pharmacies, especially during the first weeks of the COVID-19 pandemic. This context led to the softening of compliance with technical requirements of good manufacturing and import practices for medications and pharmaceutical supplies by the Brazilian regulatory agency ${ }^{16}$, which obligued to a greater attention in the monitoring of the quality of the products in the pharmacy services. In Mexico, the import practices were also modified and the Ministry of Health released guidelines and administrative measures to streamline the process of market authorization of medications and other health supplies coming from abroad. ${ }^{17}$ In a general manner, in Brazil and Argentina, there was the perception of limited support from the authorities regarding product import.

With the change in the dynamics of medium- and high-complexity care and with the expansion in the number of hospital beds in a short period of time, the offer of various supplies was drastically influenced worldwide. Dependence on supply imports from India and China, as well as the limited productive capacity of national companies, hindered the scheduling and acquisition activities. Consequently, the lack of various products contributed to price rises at the beginning of the pandemic.

This condition implied the need for the health services to reallocate resources and redefine priorities, considering budget planning. The rationalization of financial resources and the austerity policies implemented showed to be important strategies in facing the pandemic. In the specific context of public acquisitions in Brazil, an extra challenge for the hospitals was managing the requests of price modifications by the providers with contrabcts already in force, as expected in a scenario of reduced offer and instability in several levels of the productive chain.

Shortage of medications led to the search of the evidence of effectiveness and safety for potential therapeutic alternatives and the systematization of the data referring to the contacts previously established and to the creation of new clinical guidelines. The need to monitor drug use and safety was a concern of the European Medicines Agency (EMA) European regulatory agency and of the Food and Drug Administration (FDA), which reinforced the importance of adverse event notifications during the pandemic and indicated priorities for pharmacovigillance. ${ }^{16}$

New rules for circulation or isolation of wards and other hospital sectors restricted the pharmacists' access to patients and to other members of the health team, as well as limited the conduction of team meetings, requiring the use of social networks and online platforms. It was necessary to restructure the drug distribution systems, with the reformulation of the shifts and schedules, and the definition of new rules for returning and cleaning the supplies received.

When facing disasters, the following is expected: (i) analysis of the context and damages, (ii) coordination of activities, and (iii) reorganization of the services, previously mentioned. Nevertheless, the mobilization of human resources is also mentioned as one of the responses in context of health emergencies..$^{18}$ And this showed to be one of the most challenging aspects for the services. Hiring intering pharmacists with little or no training was sought at the beginning of the pandemic. Part of the team suffered the effects of non-availability and insecurity in the use of personal protective equipment, overload, emotional exhaustion, and occupational exposure to the new Coronavirus, leading them to develop the disease with severe clinical conditions and even death. This accelerated mobilization of human resources also affected medical and nursing teams, resulting in major heterogeneity of professional experiences and practice standards, which directly impacted on Pharmacy services.

Such challenges and the level of importance for the pharmaceutical services are shown in Figure 1, according to the authors' experience.

Figure 1. Synthesis of the main challenges faced by the Pharmacy Services during the COVID-19 pandemic.

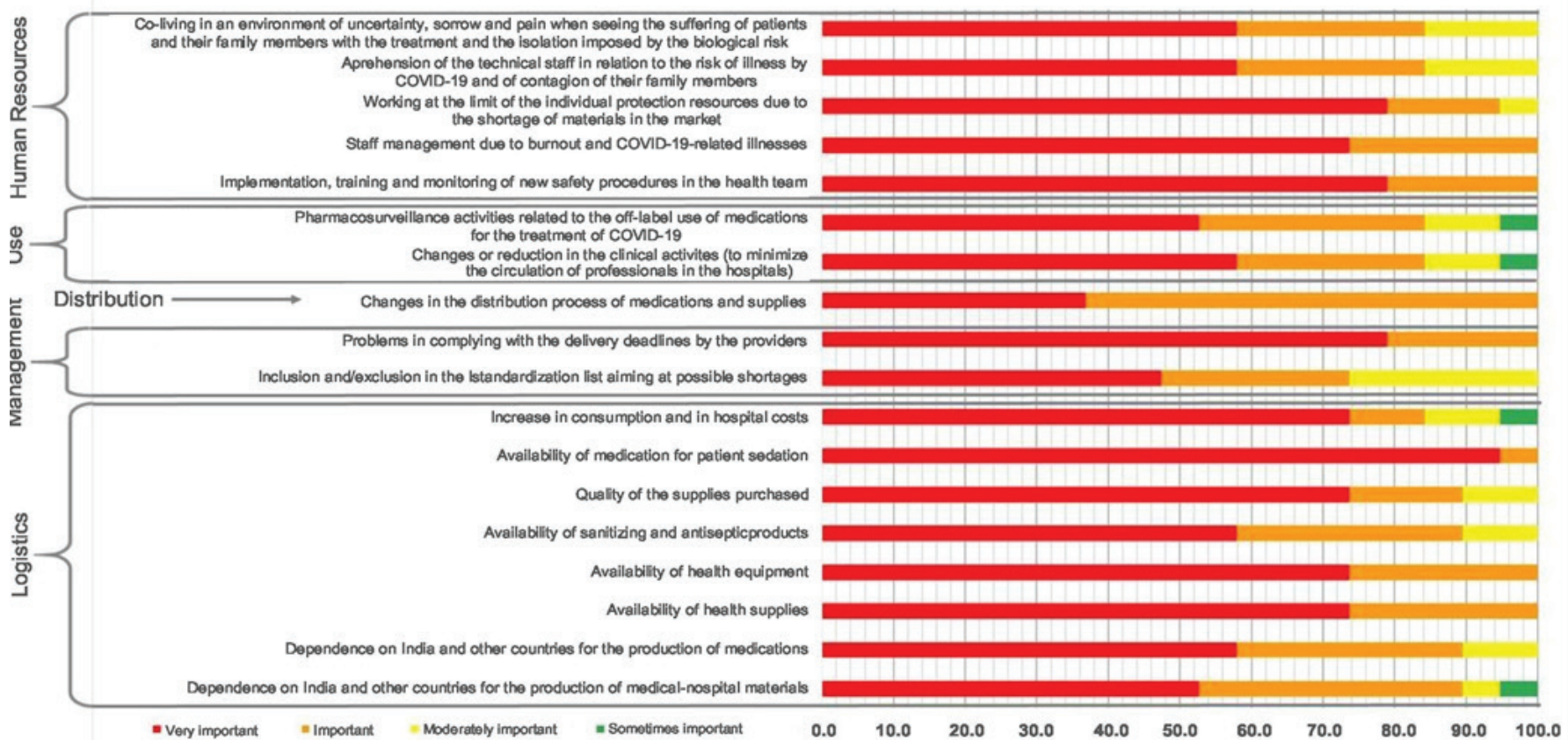

Note: The level of importance of the items was indicated by each of the 24 authors of this text, totaling $100 \%$. 


\section{Possible changes and future impacts}

\section{For the management of pharmacy services}

Various transformations, with possible short- and medium-term impacts, took place in the hospital pharmacy services. In a positive sense, the institutionalization of conducts stands out. This is a vital process for care effectiveness and safety. It is believed that the experience lived during the pandemic will contribute to the creation of a culture of process standardization with clear actions and definition of the activities of the actors involved, promoting continuous improvement in quality.

The drug information activity, performed by the pharmacists, also seems to have been strengthened during the period. Physicians, nurses and other health professionals started to systematically request to the pharmacy services in the search of reliable, updated, and unbiased information. This practice has promoted greater trustworthiness of the professional performance and may have contributed to establish safer care practices. ${ }^{18}$ It is also an important mechanism for strengthening the relationships between the healthcare professionals and the inter-disciplinary work, in the short- and medium-term.

Another considerable change in logistics is related to the medications and supplies highly consumed in hospitals. The main strategies adopted by the services, either public or private, involved the following: i) flexibilization (previously mentioned) in the processes for the certification of providers and for technical qualification of the products, ${ }^{20}$ due to the need to incorporate new technologies in the units or as a strategy to manage shortages; ii) strengthening of the cooperation between institutions, both for the exchange of managerial and care information and to prevent stock disruptions; iii) streamlining of medication and supply stocks related to the COVID-19 treatment, with the aim of favoring control and minimizing the impacts on morbidity and mortality related to the disease; iv) centralization of drug purchases by promoting equitable access in the case of Mexico; and $v$ ) consolidation of the Drug and Therapeutics Committee (Comissão de Farmácia e Terapêutica, CFT) in the management of the list of medications selected and in establishing clinical protocols and therapy guidelines in the institutions. It is true that these conducts will have to be sustained in the future.

In relation to the variations in the prices of medications and the expected requests for their repositioning, presented by the providers, especially in the case of public acquisitions in Brazil, it is important that the hospitals use the resources provided according to the regulations in force seeking to prevent potentially excessive rises. This can be achieved by demanding from the providers formal reasons with solid grounds for the increase in the previously agreed upon values. This option is important to promote a sustainable balance between the finances of the public hospitals and the survival of the suppliers. If insufficient, the hospitals will need to expand their controls on the medications and supplies consumed, by means of traceability mechanisms, as well as to re-evaluate and discuss funding sources or realignment of reimbursement charts, so as to ensure their functioning ${ }^{16}$. It is inferred that this learning will bring about great contributions to the future of the pharmaceutical services, promoting greater efficiency in the use of the resources and cost reductions, in addition to expanding patient safety.

Establishing contingency plans and the improvements in the planning and risk management processes were essential for facing the pandemic. It is crucial that new strategies are discussed and applied seeking to prevent or mitigate the problems resulting from emergency situations. It is understood that this will be a measure which will begin to be employed by the pharmacy services as a way to prevent new disruptive changes.

The investment in electronic medical charts and prescriptions showed to be an essential tool, both to reduce the transmission risks of the new coronavirus by the handling of physical documents and for its advantages regarding administrative tasks and patient safety. The use of the digital resources in managerial, logistic and assistance activities was expanded during the pandemic, being considered as an important legacy for the pharmaceutical services in the improvement of the work processes. Some of the structuring activities of Hospital Pharmacy have good potential for adaptation to the remote model, with the possibility of even resulting in an increase in productivity. The pharmacists' remote access to the computerized systems of the hospitals allows monitoring stocks, communication with the acquisition sectors of the hospital and with providers, which can have a positive impact on the activities of the Pharmaceutical Supply Centers, which are under intense demand during the pandemic. In relation to the drug distribution systems, the daily remote analysis of electronic prescriptions can also be of great use in the redistribution of the tasks of the inperson and remote work teams.

\section{For Pharmaceutical Care}

The prescription and use of off-label medications were introduced in the routine of many hospitals for COVID-19 management. According to the diverse scientific evidence available up to the moment, there is no single medication with proven efficacy and safety for treating the infection caused by SARS-Cov- $2 .{ }^{21}$ In a setting with so many uncertainties, pharmacists have played an essential role in the multidisciplinary teams. The patients at higher risk of developing complications, such as those of advanced aged and with chronic diseases, generally use several medications and are therefore more subjected to drug interactions and adverse events, a situation that is worsened by the concomitant use of experimental therapies for the treatment of COVID-19. ${ }^{22}$ In this context, clinical pharmacists play a vital role in drug reconciliation, in the review of the pharmacotherapy prescribed, and in the management of drug therapy, especially in patients with chronic diseases and hospitalized in intensive care units, thus contributing for better cure rates..$^{18,23}$

In addition to the routine clinical activities, some institutions implemented additional strategies for the active monitoring of patients, encompassing the following: (I) ensuring the adequate use of all the medications recommended for the management of COVID-19 cases, by elaborating and implementing clinical protocols; (ii) monitoring of adverse drug reactions such as fatigue, fever and hepatotoxicity, with event notifications for strengthening the pharmacovigillance actions; and (iii) strengthening the online clinical support for the multidisciplinary team. ${ }^{4,18,24}$.

The pharmacists' participation in programs for managing the use of antimicrobials has contributed to the quality of medication use during the pandemic, ${ }^{25}$ with the development of protocols for local treatment and monitoring of patients with bacterial co-infections..$^{25-27}$ The inadequate use of antimicrobials in the management of COVID-19 can increase microbial resistance and the prevalence of adverse events..$^{18,26-28}$ 
The COVID-19 pandemic has been a great challenge, but also an opportunity to develop pharmaceutical practice, driving the development of remote and innovating pharmaceutical services. ${ }^{18}$ The hospital pharmacy services showed their ability to react to a health crisis, adapting to maintain their responsibility in pharmaceutical care, even in the face of the restricted access to the other professionals of the health team. ${ }^{29}$ One of the tools adopted was the telepharmacy, 4,18,29 defined as the "use of telecommunication technology to facilitate or allow the provision of high-quality clinical services, in situations where the patient or the health team do not have (in-person) contact with the pharmacy team..$^{29,30}$

A study conducted in Wuhan, China, demonstarted that the full use of information technology to provide pharmaceutical care not only avoided unnecessary cross-infections, but also optimized essential resources, such as personal protection equipment, so that the limited resources could be used in places with greater needs. ${ }^{4}$

In view of the complexity of the disease, the prolonged hospitalization time, and the possibility of sequelae, pharmaceutical care for COVID-19 cases tends to exceed the hospital setting. The pharmaceutical services provided at the moments of care transition, especially at hospital discharge, reduce the number of hospital readmissions and the use of intensive care units, improve patient safety and satisfaction, and reduce health costs. ${ }^{31}$ Care transition between the different levels of health care demands the use of effective communication strategies, and the remote service tools were successfully used, according to the experience of some specialists. In other cases, however, chronic patients in follow-up experienced worsening in their clinical conditions, due to the spacing or cancellation of medical or pharmaceutical appointments imposed by limitations in locomotion or transportation.

The expectation is that telepharmacy will be incorporated as a complementary tool, in a mixed model of pharmaceutical care and adapted to the individual needs of the patients.

\section{Final Considerations}

The production of medications and other health products, centralized in few countries, seems to be economically feasible, but generated instability in provision due to logistic difficulties, challenging the services in anticipating the needs and in stock constitution or replenishment. In addition, various concerns on the quality of new products introduced in the market and the higher exposure to the off label use of medications impacted on the monitoring and pharmacovigllance actions.

Multiprofessional integration, extremely intensified in hospital capacities reduction times like those observed durin pandemics, demonstrated being necessary for a safer and more comprehensive care.

Actions that promote proximity between teams, ease of communication, and shared point of views on work processes enable a myriad of learning opportunities, humanization of the inter-professional relationships and more dynamic and conclusive decision-making.

Remote care impacted on many working environments in the world and hospital pharmacy was not different. The potentialities of this working method, either in hybrid/semi-in-person or entirely remote models, can induce important positive effects on productivity, on safety, and even on professionals quality of life; and this method can be considered in a permanent manner or as contingency plans, in addition to the fact that they promote greater integration between pharmacists and patients, thus creating a relationship of confidence and engagement for better medication adherence.

\section{Funding sources}

This article did not receive funding.

\section{Collaborators}

$\mathrm{ACM}$ and $\mathrm{ECL}$ conceived this text and conducted the discussion of the theme with ARS, MJS, RCN, FFL, AMM, CLO, CAT, CSO, DC, EDN, FF, JAC, LICP, LFC, PB, RO, SRC, SDM, THG, VSB, VS, and VBP. The text was written by ACM, ARS, ECL, MJS and RM. All the authors evaluated, critically reviewed, and approved the final version of the article.

\section{Conflict of interests statement}

The authors declare that there is no conflict of interests in this article.

\section{References}

1. Goff DA, Ashiru-Oredope D, Cairns KA, et al. Global Contributions of Pharmacists During the COVID-19 Pandemic. J Am Coll Clin Pharm. 2020;(August):1-13.

2. Ying W, Qian Y, Kun Z. Drugs supply and pharmaceutical care management practices at a designated hospital during the COVID-19 epidemic. Res Soc Adm Pharm. 2020;(April):0-1.

3. Arain S, Thalapparambath R, Al Ghamdi FH. COVID-19 pandemic: Response plan by the Johns Hopkins Aramco Healthcare inpatient pharmacy department. Res Soc Adm Pharm. 2020;(May):0-1.

4. Hua X, Gu M, Zeng F, et al. Pharmacy administration and pharmaceutical care practice in a module hospital during the COVID-19 epidemic. J Am Pharm Assoc. 2020;60(3):431-438. e1.

5. Montmeat D, Gard C, Raux M, et al. Shortage of sedatives and neuromuscular blockers during COVID-19 pandemic: The result of an overstocking procedure in French hospitals? Anaesth Crit Care Pain Med. 2020;39(5):585-6.

6. Visacri MB, Figueiredo IV, Lima TM. Role of pharmacist during the COVID-19 pandemic: A scoping review. Res Soc Adm Pharm. 2020;(January).

7. Claire Elson E, Oermann C, Duehlmeyer S, et al. Use of telemedicine to provide clinical pharmacy services during the SARS-CoV-2 pandemic. Am J Heal Pharm. 2020;77(13):10056.

8. Tortajada-Goitia B, Morillo-Verdugo R, Margusino-Framiñán $L$, et al. Survey on the situation of telepharmacy as 
applied to the outpatient care in hospital pharmacy departments in Spain during the COVID-19 pandemic. Farm Hosp. 2020;44(4):135-40.

9. Advisory FIPH., Pharmacists GFOR., Workforce THEP. Updated 26 March 2020 Fip Health Advisory Guidelines for Pharmacists and the Pharmacy Workforce. 2020;(March):0-48.

10. Sociedad Española de Farmacia Hospitalaria. Gestión de la crisis COVID-19. Revista Farmacia Hospitalaria. Disponível em: https://www.sefh.es/revista-farmacia-hospitalaria. php?id=196\&anio=2020. Acesso em 23 de novembro 2020.

11. Society of Infectious Diseases Pharmacists. COVID-19 Resources. Disponível em: https://sidp.org/covid19/. Acesso em 23 de novembro 2020.

12. 12. Sociedad Chilena de Farmacia Asistencial. COVID-19. Disponível em: http://schfa.cl/covid-19/. Acesso em 23 de novembro 2020.

13. Sociedade Brasileira de Farmácia Hospitalar e Serviço de Saúde. Plano de contingência em diversos cenários farmacêuticos no âmbito da pandemia por COVID-19. 2020.

14. Ordem de Farmacêuticos de Portugal. Plano de Contingência - COVID-19 - Farmácia 2020:1-71. Disponível em: https:// www.ordemfarmaceuticos.pt/fotos/editor2/2019/ WWW/campanhas/coronavirus/V5_Plano_de Contingencia_03_04_2020.pdf. Acesso em 23 de novembro 2020.

15. Likert R. A technique for the measurement of attitudes. Arch Psychology. 1932; 22(140):55.

16. Pimental A, Fernandes TB, Lima EC, et al. Notificação de eventos adversos a medicamentos e vacinas. Boletim Observium; 2020; Edição Especial COVID-19 (4) Esp:0-2.

17. DOF. Acuerdo por el que se establecen medidas administrativas para agilizar el trámite de registro sanitario de medicamentos y demás insumos para la salud que provengan del extranjero. 2020. https://www.dof.gob.mx/nota_detalle. php?codigo $=5605237 \&$ fecha $=18 / 11 / 2020$. Acesso em 30 de nov 2020

18. Quarantelli EL. Ten criteria for evaluating the management of community disasters. Disasters 1997; 21:39-56.

19. Liu $S$, Luo $P$, Tang $M$, et al. Providing pharmacy services during the coronavirus pandemic. Int J Clin Pharm. 2020;42: 299304.

20. BRASIL. Ministério da Saúde. Agência Nacional de Vigilância Sanitária. ANVISA. Resolução de diretoria colegiada- RDC no 392, de 26 de maio de 2020 2020. Disponível em: https:// www.in.gov.br/web/dou/-/resolucao-de-diretoria-colegiadardc-n-392-de-26-de-maio-de-2020-258912696. Acesso em 23 de nov 2020.

21. Andrade KRC, Carvalho VKS, Lima AA, et al. Pharmacological therapies for patients with human coronavirus infections: a rapid systematic review. Ciênc. saúde coletiva. 2020; 25(9): 3517-3554.

22. Song $\mathrm{Z}, \mathrm{Hu} \mathrm{Y}$, Zheng $\mathrm{S}$, et al. Hospital pharmacists' pharmaceutical care for hospitalized patients with COVID-19: Recommendations and guidance from clinical experience. Res Soc Adm Pharm 2020.
23. Elbeddini A, Prabaharan T, Almasalkhi S, et al. Pharmacists and COVID-19. J Pharm Policy Pract. 2020; 13:36.

24. Margusino-Framiñán L, Illarro-Uranga A, Lorenzo-Lorenzo K, et al. Atención farmacéutica al paciente externo durante la pandemia COVID-19. Telefarmacia. Farm Hosp. 2020;44(Supl 1):S61-5.

25. Stevens MP, Patel PK, Nori P. Involving antimicrobial stewardship programs in COVID-19 response efforts: all hands on deck. Infect Control Hosp Epidemiol. 2020:1-2.

26. Langford BJ, So M, Raybardhan M, et al. Bacterial co-infection and secondary infection in patients with COVID-19: a living rapid review and meta-analysis. Clinical Microbiology and Infection. 2020: $\mathrm{n}(\mathrm{xxx})$.

27. Rawson TM, Moore LSP, Zhu N, et al. Bacterial and fungal coinfection in individuals with coronavirus: A rapid review to support COVID-19 antimicrobial prescribing. Clin Infect Dis. 2020; May (2):530.

28. Rawson TM, Moore LSP, Castro-Sanchez E, et al. COVID-19 and the potential long-term impact on antimicrobial resistance. J Antimicrob Chemother. 2020; 75(7):1681-1684.

29. Canadian Society of Hospital Pharmacists. Telepharmacy: Guidelines. Ottawa (ON). Canadian Society of Hospital Pharmacists; 2018. Disponível em: https://cshp.ca/sites/ default/files/files/publications/Official\%20Publications/ Telepharmacy\%20Guidelines_2018.pdf. Acesso em 11 de novembro de 2020

30. Martins MA, Reis AM. Pharmacists in response to the COVID19 pandemic in Brazil: where are we? Rev Bras Farm Hosp Serv Saude. 2020;11(3):0517.

31. Herzik KA, Bethishou L. The impact of COVID-19 on pharmacy transitions of care services. Res Social Adm Pharm. 2020:7411(20)31167-0. 